\title{
Analysis of the organic integration of non-traditional skills and country houses
}

\author{
Wei Liu ${ }^{1}$, Yu Zhou ${ }^{1}$ \\ ${ }^{1}$ Department of Design and Art, Shenyang Aerospace University, Shen Yang, Liao Ning, 110136, China
}

\begin{abstract}
In the spirit of the times that the "artisan spirit" returns, the unique traditional arts and crafts have profound strength and heritage in economy and culture. This article will discuss the integration of non-legacy traditional skills in the architecture, space, furniture, and functions of the homestay. Non-legacy traditional skills are involved in the design and transformation of the homestay. That the homestay becomes a carrier of non-legacy traditional skills, at the same time, the non-legacy traditional skills also infuse the cultural connotation of local characteristics into the country house. Its significance is to explore the innovative design of country houses, but also to explore a new model for the protection and inheritance of non-legacy traditional skills.
\end{abstract}

\section{The value of non-legacy traditional skills}

Non-legacy traditional skills, as a form of production originated from the folk, are a process specification and technical means formed by people's long-term production and life through experience and wisdom. It is the most representative form of creation in China. On the basis of meeting the needs of life, the objects produced have both artistic value. It is an important material carrier for people to obtain material use and meet cultural needs. Carrying the essence of traditional cultures. With the spirit of the times, the creatin concept returning from the "artisan spirit" is unique, which is carried by traditional

craftsmanship.

The production of non-legacy traditional skills is a process of transformation from heart to hand, from inside to outside. The products created are characterized by "fine" and "specialized". People apply their experience in production, and their understanding and realizations about society nature, universe also included in the shaping or clecoration of objects, that is, they meet the needs of people 's lives and spiritual needs, and their inner culture also models people 's living habits and Social psychology. It is this tangible material that carries the intangible culture and builds the unique cultural characteristics and national characteristics of the Chinese nation.

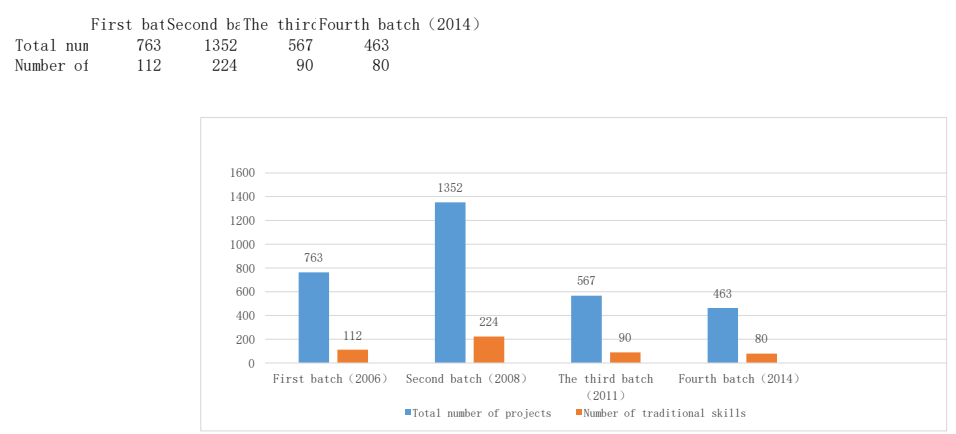

Figure 1. The proportion of traditional skills in non-legacy projects

\section{Non-legacy culture and homestay development}

The homestay is a family-run business unit, providing visitors with a reception place to experience the local lifestyle and local customs. With the development of the tourism industry in recent years, there has been a spurt-like development of homestays. Due to the short development time and rapid development speed, the problems will inevitably emerge. The operator's definition of the concept of the homestay is unclear, and the homestay design is just a reproclution, which is, same as the successful case, without feed local characteristics

*Corresponding author's e-mail: 1337998660@qq.com 
and customs into the homestay designs, so the homogeneity and monotony problems are everyed. The operator has insufficient experience in the service and management of the homestay, also leads to the tourists not having a good experience.

With the increase in people's travel needs, the homestay provides tourists with more than just a living function. When meeting their living needs, they also hope to gain a search for local characteristics and cultures. Non-legacy traditional skills are forms of creation with regional and national characteristics formed by people in production and life, which can best reflect the life wisdom and spiritual culture of local residents. Therefore, relying on non-legacy traditional skills as a cultural carrier, the homestay develops in the direction of characterization and diversification, which enables the non-legacy traditional skills to be activated and inherited while also bringing great development to the homestay industry.

\section{Organic integration of country house and non-legacy traditional skills}

\subsection{The organic integration of house renovation and traditional building construction skills}

The renovation of the homestay is not simply a functional transformation. Residents often choose bed and breakfasts in order to seek different regional living experiences request. there fore the building renovation must meet the functional requirements and comfort, at the same time the homestay also need to have the characteristics of traditional local architecture.

There are as many as 35 traditional building skills in non-legacy traditional skills. According to sorting and statistics, it can be divided into regional folk house building skills, national folk house building skills and gardening skills. Whether it is the craftsmanship of the Xiangshanbang traditional building with exquisite

Table 1. Classification of traditional building construction skills craftsmanship or the Hakka earthen building built with the clan blood as a link, it reflects the superb architectural skills of the Chinese traditional building construction craftsmen according to local conditions, the application of materials, and the unique national cultural characteristics.

The first thing to traditional building renovation is to respect the original form of the building. As a symbol of a region or a nation, the architectural form is often as a reflection of regionality and nationality. For example, the unique shape of the "square" and "round" of the Hakka earth building expression the unique defense function of the building. In the form of clan aggregation, it display the Hakka clan blood structure and clan cohesion. Therefore, the original form of the building should be preserved during the renovation process.

Secondly, in the early stage of the transformation of traditional buildings, we must fully understand the architectural skills of local houses. The traditional architectural skills in herited through generation to generation must be the most suitable local construction methods. For example, kiln cave building skills, local people adjust measures to local conditions, combined with the complex landforms of the Loess Plateau, excavated kiln caves, to create the most comfortable residence in harsh environments. using local traditional architecture building skills and combine regional cultural characteristics to optimize the design of the homestay building.

Finally, while respecting the original appearance of the building and building skills heed based on traditional architecture mean while, it is also necessary to consider the formation of the space and the division of functions. Reasonably divide the space's function and go as to improve the use efficiency. It is necessary to consider the circulation between each space and the privacy of a single space. Make space function reasonable and flexible to meet the needs of residents.

\begin{tabular}{|l|l|}
\hline $\begin{array}{l}\text { Local folk } \\
\text { house building } \\
\text { skills }\end{array}$ & $\begin{array}{l}\text { Xiangshan Bang Traditional Building Construction, Wuzhou Traditional Residential } \\
\text { Building Construction, Hui Zhou Traditional Residential Building Construction, Minnan } \\
\text { Traditional Residential Building Construction, Cave Construction, Beijing Siheyuan } \\
\text { Traditional Construction Skills, Yanmen Residential Construction, Shikumen Lane } \\
\text { Building Construction, Luling Traditional Residential Construction }\end{array}$ \\
\hline $\begin{array}{l}\text { National folk } \\
\text { house building } \\
\text { skills }\end{array}$ & $\begin{array}{l}\text { Construction of Hakka Earth Buildings, Construction of Traditional Wooden Structures } \\
\text { of Dong Nationality, Construction of Traditional Miaozhai Diaojiaolou, Mongolian } \\
\text { Yurts, Construction of Li Boat Houses, Construction of Kazakh Felt Houses, } \\
\text { Construction of Russian Houses, Construction of Salar Fences, Construction of Tibetan, } \\
\text { Qiang Diaolou, Hakka Tulou building, Tujia Diaojiao building, Uygur residential } \\
\text { building technigue }\end{array}$ \\
\hline $\begin{array}{l}\text { Other building } \\
\text { skills }\end{array}$ & $\begin{array}{l}\text { Wooden arch bridge traditional construction skills, stone bridge construction, traditional } \\
\text { gardening skills, ancient stage construction, ancient building restoration skills }\end{array}$ \\
\hline
\end{tabular}

\subsection{Organic integration of homestay furniture design and traditional furniture making skills}

The homestay's furniture is touched and used by residents during the living, which can bring the most intuitive feeling to the residents. Appropriate furniture can bring occupants comfort, at the same time, it can also bring different spiritual feelings residents through their inner culture. At present, the design style of the homestay 
generally tends to simple and natural rural style, and its furniture has not been unified with the overall design. According to the survey, the following problems are commonly found in the design of homestay furniture: 1. The homestay furniture style only replicates the standard hotel furniture style, and the homestay cannot form a unified style as a whole. Second, the style is chaotic. The mixed use of different styles of furniture, or the random accumulation of cultural elements in some furniture, and the penetration of different techniques, make the furniture style incomprehensible.

Wood belongs to the East, and the Chinese have been keen on the use of wood in the construction since ancient times. Wood has the advantages of convenient material extraction and good plasticity. Therefore, most of the traditional Chinese furniture's materids are wood. The production of traditional Chinese furniture based on wood has the following characteristics: First, the materials used are exquisite. the texture of furniture material is smoothly and meticulous. In the process of choice of materials for fabricating furniture, the artisans first of all consider to use the durable sandalwood, rosewood, mahogany, etc. are often the first choice. Second, the process is complex. Craftsmen often have to go through dozens of procedures, carefully polished, and carefully carved to form an excellent piece of furniture. Third, the decoration is skillful. The decoration techniques of furniture of different systems are also complicated and varied. Such as openwork, relief and other processes. Fourth, the system is exquisite. China has a vast territory, with different lifestyles and cultural types either in the north or in the south. Therefore, the types of traditional furniture also have their own systems, and the furniture shapes of different systems are also different. For example, Cantonese-style furniture concentrates eestern and Western culture in the one. Ming-style furniture is simple and elegant. Fifth, there are many kinds. The types of furniture created by Chinese traditional furniture range from daily tables and chairs to literati's scented tables and blogs that pursue the taste of life. Chinese traditional furniture is both practical and artistic, and can fully meet the functional and characteristic needs of the homestay.

Traditional furniture should pay attention to rationality, practicality, functionality and decoration in the homestay. First of all, we must find the most suitable furniture form for the homestay, grasp the reasonable scale, and achieve harmony with the overall environment. Secondly, to meet the functional requirements. Finally, we must explore the cultural connotation contained in traditional furniture. Refining its cultural elements, structural characteristics and workmanship, reasonable innovation, and strive to create the most suitable furniture for the characteristics of the homestay. Innovating in protection and adapting to modern needs is the better inheritance.

\subsection{The organic integration of home furnishings and traditional local craftsmanship}

Furnishing design emphasizes the organic integration of space aesthetics, life functions, feng shui culture and other functions in the space. Pay attention to using objects to shape the space environment. The role of furnishing design: First, divide the space. Using objects to divide the space to meet the needs of life functions. Meeting the visual aesthetic needs. Second, create a space atmosphere and convey cultural information. 3 . Optimize the space. Reasonable use of the size, material, color, and orientation of items to improve the living environment.

The homestay provides cultural information with a local living environment and regional characteristic. The furnishings of the homestay use actual utensils to decorate the space, which can directly convey cultural information. Traditional handicraft skills (such as: pottery, porcelain, lacquer, fabric, etc.) create objects that are the main purpose of people to meet the needs of life, but also meet the aesthetic needs. Therefore, traditional hand-crafted utensils are the best choice for furnishings in the homestay.

Pottery, porcelain and lacquer have their own practical features, and the use of utensil modeling and painting, carving and other techniques to make ceramics obtain extremely high aesthetic value. Pottery, porcelain and lacquer are the first choice for tableware and tea sets, followed by ceramics for vases, incense burners, etc. The use of ceramics and lacquerware in the furnishings of the homestay not only meets the practical requirements but also enriches the decorativeness.

Traditional fabric can play an important role on partition design. In addition, the wall is the most basic form to space division, the use of partitions in order to divide the space is more flexible, and can achieve the visual effect of the combination of virtual and real. And the materials, patterns and colors of traditional fabrics make the homestay more traditional.

In addition, glass, gold and silverware, etc. all have the extremely using function in the home furnishing design. In short, the traditional hand-made utensils should be used reasonably in the interior furnishings of the homestay to give full play to the artistic design of the furnishings. It can better convey traditional skills and cultures, and provide residents with regional characteristics of living experience.

\subsection{Organic integration of fabrics and traditional dyeing and weaving skills in the indoor soft environment of the homestay}

The non-legacy traditional skills are very rich in weaving skills, such as: silk, brocade, weaving and embroidery, spinning and dyeing, printing and dyeing, tie dyeing, batik and so on. Due to differences in nationality and regionality, each has its own characteristics. The use of traditional weaving techniques in the design of a soft space environment can enrich the choice of soft furnishings in the homestay, and at the same time, it is also an inheritance of traditional weaving techniques and enrich understanding of traditional weaving and dyeing culture.

For the application of weaving techniques in a soft 
environment, we can first start from the material, choosing according to the different texture materials to depend if use. For example, softer materials can be used on linen. Linen is a room item which is directly contact with the human body. It is widely used in homestay space and it is the main component and element in the space environment. It reveals the materials, colors, forms and elements and all together construct the space and shapes with morphological characteristics. The linen is the prominent point of the overall harmony of the space. It should be coordinated with the environment in the use of traditional weaving and embroidering. On the one hand, it reflects the characteristics of traditional weaving skills and the bearing of the national regional culture. on the other hand, we can proceed from the technique. Each weaving technique has its own different expressions. Skills such as silk weaving, embroidery, printing and dyeing can be integrated with the brand of the homestay, and its brand LOGO is displayed on linen, curtains and other items through different weaving techniques. It is not only the display of traditional skills but also the shaping of brand culture. Finally, starting from cultural elements, traditional weaving techniques are rich in patterns, including geometric patterns, animal patterns, plant patterns, characters, auspicious patterns, etc. Most of them show awe of nature, longing for a better life, pursuit of art, and expression of beauty. Weaving skills of different regions and different nationalities also have their own characteristics. Understanding the connotation behind its elements and extract suitable traditional patterns to be used in decorative paintings, lighting, wall coverings, and background walls. Paying more attention to the suitability of the decoration, rather than complicated, to achieve harmony and unity with the overall environment.

\subsection{Relying on traditional skills to create experiential learning theme homestay}

With the increasing demand from tourists, people appreciate the complex and delicate craftsmanship and utensils of traditional craftsmanship while exuding their unique charm, and they are more willing to understand the production process and the cultural connotation behind it. Or participate in the production of utensils and enjoy the process of participating.

Relying on traditional skills to create an experience-learning theme homestay needs to discover suitable skills. Such as: pottery, porcelain, lacquer making, weaving skills, gold and silver forging skills, and special diet making skills can all be the basis of the experience-learning homestay. Invite skill inheritors to settle in. At this time the homestay is no longer for tourism. It exists independently of tourism. The main purpose of the residents is to learn and experience traditional skills. After work, find a clean place to cultivate body and mind development. The creation of this model will enable homestays to develop independently from the constraints of tourism. At the same time, this is also one more choice to inherite the traditional skills.

\section{Conclusion}

Non-legacy traditional skills and homestay are both a simple and authentic way of life, both of which have local and regional characteristics. They are all long-standing local cultural carriers of the Chinese nation. This article combines the tangible material and the intangible culture of non-legacy traditional skills in the design of the homestay, so that the non-legacy traditional skills can be activated and protected and it also can explore more paths for the localization, specialization and culture injection in the homestay design.

\section{Acknowledgments}

This article is the staged result of the 2018 Shenyang City Philosophy and Social Science Planning Project of Liaoning Province, "Shenyang General Aviation Characteristic Cultural Tourism Town Construction Model Study" (project number 18031).

\section{References}

1. Zhu, S.J., Yang, Q.T. (2019) Problems and countermeasures in the development of country house. Southern Agriculture. 13: 81-82.

2. Zhang, X. (2016) The Expression Form of Local Culture in Bed and Breakfast: Return and Construction. Journal of Minjiang University. 37: 114-121.

3. Zhao, J. (2017) On the characteristics and development trend of contemporary bed and breakfast design. Art and Design (Theory). 2: 55-57.

4. Zhang, X. (2013) Traditional building skills in the view of intangible cultural heritage. In: Chinese Cultural Heritage. 114-121.

5. Zhou, F. (2019) Innovative Application of Chinese Traditional Patterns in Interior Soft Decoration Design. Building Materials and Decoration. 118-119. 